\title{
DISTRIBUIÇÃO DO AMÔNIO, NITRATO, POTÁSSIO E FÓSFORO EM COLUNAS DE LATOSSOLOS FERTIRRIGADAS ${ }^{(1)}$
}

\author{
Guilherme Kangussu Donagemma ${ }^{(2)}$, Hugo Alberto Ruiz ${ }^{(3)}$, Víctor \\ Hugo Alvarez V. ${ }^{(3)}$, Paulo Afonso Ferreira ${ }^{(4)}$, Reinaldo Bertola \\ Cantarutti $^{(3)}$, Agno Tadeu da Silva ${ }^{(5)}$ \& Getulio Coutinho \\ Figueiredo $^{(6)}$
}

\begin{abstract}
RESUMO
Na fertirrigação, é conveniente aplicar os nutrientes de forma a conseguir sua localização na profundidade mais adequada para absorção por parte das culturas: em maior profundidadepara a cultura perene e, mais superficialmente, nas culturas de ciclo curto. Com os objetivos de estabelecer em que fração da lâmina de irrigação devem ser aplicada as doses de $\mathrm{N}\left(\mathrm{NH}_{4}{ }^{+}\right.$e $\left.\mathrm{NO}_{3}{ }^{-}\right) ; \mathrm{K}^{+} \mathrm{e}_{2} \mathrm{PO}_{4}{ }^{-}$, de investigar qual o melhor fracionamento de suas doses, de modo a localizá-los na profundidade adequada, e de determinar a distribuição na coluna de $\mathrm{NH}_{4}^{+}, \mathrm{NO}_{3}^{-}, \mathrm{K}^{+} \mathrm{e}_{2} \mathrm{PO}_{4}^{-}$ aplicados por fertirrigação, foi realizado um experimento em laboratório, utilizando colunas de percolação. Os tratamentos corresponderam a um fatorial $4(1+7)$, sendo quatro Latossolos de Minas Gerais [dois Latossolos Vermelho-Amarelos distróficos (LVAd1 e LVAd2), um Latossolo Vermelho distroférrico (LVdf) e um Latossolo Vermelho distrófico (LVd)], uma testemunha (aplicação de água deionizada) e sete formas de aplicação de $1 \mathrm{mmol} \mathrm{dm}-3 \mathrm{de}^{-1} \mathrm{NH}_{4}^{+}, 1 \mathrm{mmol} \mathrm{dm}^{-3} \mathrm{de}$ $\mathrm{NO}_{3}^{-}, 2 \mathrm{mmol} \mathrm{dm} \mathrm{de} \mathrm{K}^{+} \mathrm{e} 0,667 \mathrm{mmol} \mathrm{dm}^{-3} \mathrm{de}_{2} \mathrm{PO}_{4}^{-}$. A lâmina de água foi dividida em cinco frações iguais $\left(F_{1}\right.$ a $\left.F_{5}\right)$ e a dose dos nutrientes aplicada integralmente (D), ou fracionada em duas $\left(D_{1 / 2}\right)$ ou em três vezes $\left(D_{1 / 3}\right)$. Assim, a aplicação dos nutrientes foi feita segundo o esquema: $F_{2} D, F_{3} D, F_{4} D, F_{2} D_{1 / 2} F_{3} D_{1 / 2}, F_{3} D_{1 / 2} F_{4} D_{1 / 2}$, $F_{2} D_{1 / 2} F_{4} D_{1 / 2}$ ou $F_{2} D_{1 / 3} F_{3} D_{1 / 3} F_{4} D_{1 / 3}$. Subamostras foram utilizadas na análise de $\mathrm{NH}_{4}^{+} ; \mathrm{NO}_{3}^{-} ; \mathrm{K}^{+} \mathrm{e} \mathrm{H}_{2} \mathrm{PO}_{4}^{-}$, determinando-se a distribuição desses nutrientes na coluna de solo. A mobilidade apresentou a seguinte ordem nos solos LVAd1, LVAd2 e LVd:
\end{abstract}

\footnotetext{
(1) Parte da Tese de Doutorado do primeiro autor apresentada à Universidade Federal de Viçosa. Recebido para publicação em agosto de 2006 e aprovado em setembro de 2008.

${ }^{(2)}$ Pesquisador da Empresa Brasileira de Pesquisa Agropecuária - Embrapa Solos. Rua Jardim Botânico 1024, CEP 22460-000 Rio de Janeiro (RJ). E-mail: donagemma@cnps.embrapa.br

(3) Professor do Departamento de Solos, Universidade Federal de Viçosa - UFV. Av. PH Rolfs s/n, CEP 36570-000 Viçosa (MG). Bolsista do CNPq. E-mail: hruiz@ufv.br; vhav@ufv.br; cantarutti@ufv.br

(4) Professor do Departamento de Engenharia Agrícola, UFV. Bolsista do CNPq. E-mail: pafonso@ufv.br

(5) Pesquisador do Instituto Capixaba de Pesquisa, Assistência Técnica e Extensão Rural - INCAPER. Rua São Joaquim 70, CEP 29375-000 Venda Nova do Imigrante (ES). E-mail: agnosilva@yahoo.com.br

(6) Pós-Graduando do Curso de Solos e Nutrição de Plantas, UFV. E-mail: getulicf@gmail.com.br
} 
$\mathrm{NO}_{3}{ }^{-}>\mathrm{NH}_{4}{ }^{+}>\mathrm{K}^{+}>\mathrm{H}_{2} \mathrm{PO}_{4}{ }^{-}$. Já para o solo LVdf, a ordem foi $\mathrm{NH}_{4}{ }^{+}>\mathrm{NO}_{3}{ }^{-}>\mathrm{K}^{+}>$ $\mathrm{H}_{2} \mathrm{PO}_{4}{ }^{-}$. A ordem de risco de contaminação de águas subterrâneas por $\mathrm{NO}_{3}{ }^{-}$foi a seguinte: LVAd1 > LVAd2 > LVdf > LVd. A quantidade de água acrescentada a cada coluna, inferior a meio volume de poros, não foi suficiente para deslocar o $\mathrm{H}_{2} \mathrm{PO}_{4}{ }^{-}$ além do primeiro anel. Para os outros íons em estudo, a localização em maior profundidade, quando aplicados como pulso único, foi verificada com a maior concentração no pulso $\left(\mathrm{D}>\mathrm{D}_{1 / 2}>\mathrm{D}_{1 / 3}\right)$ e com a maior lâmina de água posterior à sua aplicação $\left(F_{2} D>F_{3} D>F_{4} D\right.$ e $\left.F_{2} D_{1 / 2} F_{3} D_{1 / 2}>F_{3} D_{1 / 2} F_{4} D_{1 / 2}\right)$. Os resultados evidenciam que a mobilidade diferencial de $\mathrm{N}\left(\mathrm{NH}_{4}{ }^{+}\right.$e $\left.\mathrm{NO}_{3}{ }^{-}\right)$e $\mathrm{K}^{+}$exigiria escolha cuidadosa das doses desses nutrientes na solução, a fim de evitar perdas de $\mathrm{N}$ $\left(\mathrm{NH}_{4}{ }^{+}{\mathrm{e} \mathrm{NO}_{3}}^{-}\right)$por lixiviação, ou localização excessivamente superficial do $\mathrm{K}^{+}$. A baixa mobilidade do $\mathrm{H}_{2} \mathrm{PO}_{4}{ }^{-}$mostra que a fertirrigação não seria uma técnica apropriada para sua incorporação no perfil do solo, visando à fertilização das culturas.

Termos de indexação: fertirrigação, movimento de nutrientes, nitrogênio, lâmina de irrigação e fracionamento da dose.

\title{
SUMMARY: DISTRIBUTION OF AMMONIUM, NITRATE, POTASSIUM, AND PHOSPHORUS IN COLUMNS OF FERTIGATED LATOSOLS
}

\begin{abstract}
It is convenient to apply nutrients in fertigation at an appropriate depth, in order to locate those elements at a convenient place for plant uptake. So, an experiment was carried out under laboratory conditions using percolation columns, to establish the irrigation lamina fraction in which $\mathrm{N}\left(\mathrm{NH}_{4}^{+}\right.$e $\left.\mathrm{NO}_{3}^{-}\right), \mathrm{K}^{+}$, and $\mathrm{H}_{2} \mathrm{PO}_{4}^{-}$doses must be applied as well as the optimum dose fractioning of these nutrients so as to locate their adequate depth and determine the distribution of fertigated $\mathrm{NH}_{4}^{+}, \mathrm{NO}_{3}^{-}, \mathrm{K}^{+}$, and $\mathrm{H}_{2} \mathrm{PO}_{4}^{-}$. The treatments consisted of a $4(1+7)$ factorial, using four Latosols from Minas Gerais (two dystrophic Red-Yellow, one dystroferric Red, and one dystrophic Red), a control (aplication of deionized water) and seven modes of application of $1 \mathrm{mmol} \mathrm{dm}^{-3}$ of $\mathrm{NH}_{4}^{+}, 1 \mathrm{mmol} \mathrm{dm} \mathrm{m}^{-3}$ of $\mathrm{NO}_{3}^{-}, 2 \mathrm{mmol} \mathrm{dm}^{-3}$ of $\mathrm{K}^{+}$ and $2 \mathrm{mmol} \mathrm{dm}^{-3}$ of $\mathrm{H}_{2} \mathrm{PO}_{4}^{-}$. The irrigation lamina was divided into five equal fractions $\left(F_{1}\right.$ to $\left.F_{5}\right)$ and the nutrient dose was applied whole $(D)$, or fractioned two $\left(D_{1 / 2}\right)$ or three times $\left(D_{1 / 3}\right)$. Hence, nutrient application was performed according to the following scheme: $F_{2} D$, $F_{3} D, F_{4} D, F_{2} D_{1 / 2} F_{3} D_{1 / 2}, F_{3} D_{1 / 2} F_{4} D_{1 / 2}, F_{2} D_{1 / 2} F_{4} D_{1 / 2}$ or $F_{2} D_{1 / 3} F_{3} D_{1 / 3} F_{4} D_{1 / 3}$. Sub-samples were used to analyze $\mathrm{NH}_{4}^{+}, \mathrm{NO}_{3}^{-}, \mathrm{K}^{+}$and $\mathrm{H}_{2} \mathrm{PO}_{4}^{-}$, through the determination of the profile of distribution of these nutrients. Mobility was in the following order: $\mathrm{NO}_{3}{ }^{-}>\mathrm{NH}_{4}{ }^{+}>\mathrm{K}^{+}>\mathrm{H}_{2} \mathrm{PO}_{4}{ }^{-}$, on soils LVAd1, LVAd2 and LVd. For the soil LVdf, the order was: $\mathrm{NH}_{4}^{+}>\mathrm{NO}_{3}^{-}>\mathrm{K}^{+}>\mathrm{H}_{2} \mathrm{PO}_{4}^{-}$. And the risk of contamination of ground water caused by $\mathrm{NO}_{3}{ }^{-}: L V A d 1>L V A d 2>L V d f>L V d$. The amount of water added to the column, lower than half pore per volume, was not sufficient to displace $\mathrm{H}_{2} \mathrm{PO}_{4}^{-}$beyond the first ring. Regarding the other ions studied, localization at a higher depth when applied as a single pulse, was verified with a higher pulse concentration $\left(D>D_{1 / 2}>D_{1 / 3}\right)$ and with a greater irrigation lamina following its application $\left(F_{2} D>F_{3} D>F_{4} D\right.$ and $\left.F_{2} D_{1 / 2} F_{3} D_{1 / 2}>F_{3} D_{1 / 2} F_{4} D_{1 / 2}\right)$. The results shows that the differential mobility of $\left(\mathrm{N}_{-} \mathrm{NNO}_{3}{ }^{-}\right.$e $\left.\mathrm{NH}_{4}{ }^{+}\right)$and $\mathrm{K}^{+}$would require a careful dosage of these nutrients in the solution to prevent nitrogen losses due to leaching, or excessively superficial localization of potassium. The extremely low mobility of $\mathrm{H}_{2} \mathrm{PO}_{4}^{-}$shows that fertigation would not be an appropriate technique for incorporation of this mineral into soil for crop fertilization purposes.
\end{abstract}

Index terms: fertigation, nutrient moviment, nitrogen, irrigation lamina, fratioaneted dose.

\section{INTRODUÇÃO}

A fertirrigação consiste na técnica de aplicação de fertilizantes via água de irrigação. No Brasil, essa técnica tem sido empregada principalmente no cultivo de hortaliças e fruteiras (Pinto, 2001). Essa técnica pode levar à maior eficiência da adubação, maior economia de mão-de-obra, além de melhor controle da poluição do solo.
A eficiência da fertirrigação depende basicamente da aplicação do nutriente, de modo que se concentre na profundidade de máxima densidade de raízes. Quando a lâmina de irrigação é insuficiente, os nutrientes podem se concentrar próximos à superfície do solo, ocasionando menor crescimento das raízes que exploram menor volume de solo. Nessas condições, pode ocorrer o acúmulo de sais no solo, com conseqüente elevação da pressão osmótica da solução 
acima de valores tolerados pelas plantas, diminuindo a produtividade sobretudo em regiões semi-áridas e em cultivos sob ambiente protegido. Por sua vez, a aplicação de uma lâmina de irrigação excessiva pode carrear os nutrientes para uma profundidade fora do alcance das raízes, diminuindo a eficiência da adubação, e provocar a lixiviação desses nutrientes para a água subterrânea e a conseqüente contaminação ambiental.

O manejo da fertirrigação compreende três etapas, sendo a primeira referente à aplicação de uma fração da lâmina de irrigação, a fim de permitir que a frente de molhamento atinja determinada profundidade; na segunda etapa, aplicam-se os fertilizantes dissolvidos na água de irrigação; e a terceira consiste em nova aplicação de água, para lavar o sistema e transportar os nutrientes até a zona de máxima densidade de raízes (Frizzone et al., 1985; Carrijo et al., 1999; Pinto, 2001). Este último autor sugere que se aplique um quarto da lâmina total de irrigação na primeira etapa, metade do valor na segunda e um quarto na terceira. Contudo, essas proporções não devem ser rigorosamente mantidas, pois o controle da profundidade e localização dos nutrientes deve ser feito por meio da quantidade de água aplicada na terceira etapa da fertirrigação (Hernandez, 1993).

Com relação à movimentação dos nutrientes no solo, observa-se que depende de diversos fatores, fundamentalmente da concentração do nutriente em solução, o que depende da capacidade de adsorção do elemento pelo solo (Grant \& Heaney, 1997; Qafoku et al., 2000), das cargas do complexo de troca iônica (Qafoku \& Sumner, 2001; Pinheiro, 2002), do pH (Qafoku et al., 2000), da solubilidade do fertilizante (Schumman, 2001) e das proporções dos nutrientes no fertilizante formulado (Silva, 2004). Além disso, a movimentação do nutriente depende do conteúdo de água no solo (Fesch et al., 1998; Padilla et al., 1999) e da macroporosidade do solo (Kirkby et al., 1997; Jacobsen et al., 1997; Jensen et al., 1998; Shiptalo et al., 2000). Na verdade, a movimentação de um nutriente no solo é resultado da ação simultânea dos fatores supracitados e não da ação isolada de um deles.

No caso dos Latossolos, sobretudo os argilosos oxídicos, que apresentam predomínio de cargas positivas, de modo geral o $\mathrm{N}$ é bastante móvel $\left(\mathrm{NO}_{3}{ }^{-} \mathrm{e}\right.$ $\mathrm{NH}_{4}{ }^{+}$), o K ${ }^{+}$é medianamente móvel e o $\mathrm{H}_{2} \mathrm{PO}_{4}{ }^{-}$é pouco móvel. Assim, o risco de lixiviação e contaminação de águas subterrâneas nesses solos, em geral, apresenta a seguinte ordem: $\mathrm{NO}_{3}{ }^{-}>\mathrm{NH}_{4}{ }^{+}>\mathrm{K}^{+}>\mathrm{H}_{2} \mathrm{PO}_{4}{ }^{-}$(Silva, 2004).

Com relação ao $\mathrm{K}^{+}$, Raij (1981) afirma que o risco de lixiviação desse elemento é maior nos solos arenosos e com baixo teor de matéria orgânica. No caso dos Latossolos de textura média, por apresentarem baixa proporção de cargas negativas em relação aos argilosos, oferecem maior risco de contaminar as águas subterrâneas. Em se tratando dos Latossolos argilosos oxídicos, ocorre menor retardamento do movimento do $\mathrm{K}^{+}$por predominarem cargas positivas, que repelem o $\mathrm{K}^{+}$; assim, o risco de contaminar as águas subterrâneas é maior. Nesse sentido, Wadt \& Wadt (1999), trabalhando com a lixiviação de $\mathrm{K}^{+}$em um Latossolo Vermelho-Amarelo em resposta à aplicação de duas fontes de $\mathrm{Ca}^{2+}$, sugeriram que, quanto maior a superfície protonada do solo, ou seja, com cargas positivas, menor é a afinidade do $\mathrm{K}^{+}$pela fase sólida do solo e maior é sua lixiviação. No caso de Latossolos de textura média, possivelmente haveria risco maior de lixiviação de $\mathrm{K}^{+}$do que nos Latossolos argilosos oxídicos, em razão de terem menor proporção de cargas negativas para reterem o potássio, como sugerido por Oliveira et al. (2004), que, estudando os fatores de retardamento de nutrientes em Latossolos, observaram menor fator de retardamento do $\mathrm{K}^{+}$no Latossolo com textura média.

Com relação ao movimento do $\mathrm{NO}_{3}{ }^{-}$nos Latossolos oxídicos, espera-se maior retardamento do movimento desse ânion, em razão de ter maior proporção de cargas positivas e apresentar menor risco de lixiviação de $\mathrm{NO}_{3}{ }^{-}$que os Latossolos cauliníticos. Apesar disso, Oliveira et al. (2000) e Araújo et al. (2004) afirmam que pode haver movimentação de $\mathrm{NO}_{3}^{-}$para as águas subterrâneas mesmo em Latossolos oxídicos.

Já o $\mathrm{H}_{2} \mathrm{PO}_{4}{ }^{-}$tem baixa mobilidade nos Latossolos, sobretudo nos argilosos e oxídicos, uma vez que esses solos apresentam elevada capacidade de adsorção e fixação do $\mathrm{P}$ (Novais \& Smyth, 1999). $\mathrm{O} \mathrm{H}_{2} \mathrm{PO}_{4}^{-}$fica ligado fortemente à parte sólida, não sendo facilmente liberado para a solução para ser transportado. Assim, em geral, em Latossolos o risco de lixiviação de fosfato é muito baixo. Por outro lado, a matéria orgânica exerce grande influencia na adsorção de $\mathrm{H}_{2} \mathrm{PO}_{4}^{-}$, pois interage com as cargas positivas dos óxidos, bloqueando essas cargas para adsorção do $\mathrm{P}$ (Gonçalves et al., 1985). Contudo, esse efeito é temporário (Afif et al., 1995; Andrade et al., 2003 ). Quando há aplicação continuada de matéria orgânica, como, esterco de suínos, pode haver bloqueio das cargas positivas do solo por ácidos orgânicos provenientes da decomposição do esterco. Nesse caso, o $\mathrm{H}_{2} \mathrm{PO}_{4}{ }^{-}$pode apresentar-se em forma orgânica, podendo ser lixiviado (Novais \& Smyth, 1999) e contaminar as águas subterrâneas, mesmo em Latossolos oxídicos.

Percebe-se, então, que o conhecimento do movimento de nutrientes no solo é fundamental para se propor um manejo da fertirrigação que propicie a localização deles na profundidade de máxima densidade de raízes das plantas, que em geral se concentram nos primeiros $20 \mathrm{~cm}$ (Zonta et al., 2006). Dessa forma, é aumentada a eficiência da fertirrigação, reduzindo-se a possibilidade de contaminação de água subterrânea via lixiviação de nutrientes.

Ressalta-se que a influência da irrigação e da fertirrigação na movimentação de nutrientes em solos tropicais tem sido pouco investigada. Nesse sentido, a influência da irrigação na lixiviação de nutrientes em um Latossolo Vermelho-Escuro do Cerrado foi 
estudada por Espinoza \& Reis (1984), que observaram que a maior parte da lixiviação dos nutrientes estudados $\left(\mathrm{Ca}^{2+}, \mathrm{Mg}^{2+}\right.$ e $\left.\mathrm{K}^{+}\right)$se dava nos primeiros 60 dias de irrigação. Já Villas Boas et al. (1994) avaliaram a movimentação de $\mathrm{P}$ aplicado na forma de diamônio fosfato (DAP) em resposta à fertirrigação e observaram que o $\mathrm{H}_{2} \mathrm{PO}_{4}{ }^{-}$se movimentou, vencendo a capacidade de adsorção do fósforo do solo. Esse resultado se deveu à dose aplicada, à fonte bastante solúvel e ao solo próximo de saturação pela irrigação.

Com relação ao movimento de $\mathrm{NO}_{3}{ }^{-}$no solo influenciado pela fertirrigação, Costa et al. (1999), estudando a mobilidade de $\mathrm{NO}_{3}{ }^{-}$em colunas de um Latossolo Vermelho-Amarelo fertirrigadas, observaram baixa mobilidade de nitrato (fonte: $\left.\mathrm{Ca}\left(\mathrm{NO}_{3}\right)_{2}\right)$ para as concentrações aplicadas, $830 \mathrm{e}$ $1.250 \mathrm{mg} \mathrm{L}^{-1}$. Os autores atribuíram esse resultado ao baixo conteúdo de água do solo no experimento.

Ressalta-se que são escassos, em solos tropicais, trabalhos que avaliam a influência do momento de aplicação dos nutrientes na fração da lâmina de irrigação e do fracionamento da dose de nutrientes como estratégias para aumentar a eficiência da fertirrigação e minimizar a contaminação de água subterrânea por nutrientes.

Diante do exposto, os objetivos deste trabalho foram: (a) estabelecer em que fração da lâmina de irrigação deve ser aplicada a dose de $\mathrm{N}\left(\mathrm{NO}_{3}{ }^{-}\right.$e $\left.\mathrm{NH}_{4}{ }^{+}\right), \mathrm{K}^{+} \mathrm{e}$ $\mathrm{H}_{2} \mathrm{PO}_{4}^{-}$, bem como o fracionamento dessas doses, de modo a localizá-los na profundidade adequada; e (b) avaliar a distribuição desses nutrientes, em profundidade, quando aplicados em dose integral ou fracionada, com fertirrigação.

\section{MATERIAL E MÉTODOS}

Foi realizado um ensaio de laboratório, utilizandose colunas de percolação. Os tratamentos corresponderam a um fatorial $4(1+7)$, sendo: quatro Latossolos (LVAd1, LVAd2, LVdf e LVd) de Minas Gerais (Quadro 1); uma testemunha (aplicação de água deionizada); e sete formas de aplicação das doses de nutrientes. A lâmina de água foi dividida em cinco frações iguais $\left(\mathrm{F}_{1}\right.$ a $\left.\mathrm{F}_{5}\right)$, e sempre na primeira e na última fração da lâmina de irrigação aplicou-se somente água, que é uma exigência quando se usa a fertirrigação. As doses dos nutrientes foram aplicadas integralmente $(\mathrm{D})$ ou fracionadas em duas $\left(\mathrm{D}_{1 / 2}\right)$ ou em três vezes $\left(D_{1 / 3}\right)$ - na segunda, na terceira e na quarta fração da lâmina de irrigação. Assim, as formas de aplicação foram: $\mathrm{F}_{2} \mathrm{D}, \mathrm{F}_{3} \mathrm{D}, \mathrm{F}_{4} \mathrm{D}, \mathrm{F}_{2} \mathrm{D}_{1 / 2} \mathrm{~F}_{3} \mathrm{D}_{1 / 2}$, $\mathrm{F}_{3} \mathrm{D}_{1 / 2} \mathrm{~F}_{4} \mathrm{D}_{1 / 2}, \mathrm{~F}_{2} \mathrm{D}_{1 / 2} \mathrm{~F}_{4} \mathrm{D}_{1 / 2}$ ou $\mathrm{F}_{2} \mathrm{D}_{1 / 3} \mathrm{~F}_{3} \mathrm{D}_{1 / 3} \mathrm{~F}_{4} \mathrm{D}_{1 / 3}$ (aplicação da dose integral de nutrientes na segunda fração, na terceira e na quarta; fracionadas em duas na segunda e na terceira; na terceira e na quarta, na segunda e na quarta; e das doses de nutrientes fracionadas em três e na segunda, na terceira e na quarta frações da lâmina de irrigação). As doses utilizadas são apresentadas no quadro 2.

Os tratamentos foram aplicados no delineamento experimental em blocos casualizados, com três repetições. Cada unidade experimental foi constituída por 11 anéis de PVC, com 6,6 cm de diâmetro interno e $7 \mathrm{~cm}$ de altura cada um, sobrepostos e vedados com cola de silicone nas uniões. Externamente, os anéis foram fixados com fita adesiva, para estabilizar mecanicamente a coluna, que foi preenchida com solo peneirado em malha de $4 \mathrm{~mm}$ e seco ao ar, até $7 \mathrm{~cm}$ da borda superior, formando uma coluna de $70 \mathrm{~cm}$ de altura e volume de $2,4 \mathrm{dm}^{3}$. O solo foi colocado com auxílio de funil, fazendo-se movimentos circulares para prevenir a segregação de agregados maiores no centro da coluna e, assim, alterar a seção de infiltração. Além disso, a coluna foi levemente compactada, deixando-a cair na vertical de uma altura de $0,5 \mathrm{~cm}$ do solo por três vezes, garantindo dessa forma o volume de solo desejado e minimizando o fluxo preferencial na parede da coluna. A lâmina de irrigação foi definida após testes, como aquele em que, com molhamento, atingiu o nono anel da coluna de solo $(63 \mathrm{~cm}$ de profundidade), sendo essa profundidade escolhida por exceder muito a profundidade onde estaria a maior concentração de raízes para absorver nutrientes (aproximadamente $20 \mathrm{~cm}$ ). Essa condição foi atingida dois dias após sua aplicação no solo seco ao ar com a aplicação de 360, 570, 570 e $660 \mathrm{~mL}$ de água nas colunas preenchidas com amostras dos Latossolos [Latossolos Vermelho-Amarelos (LVAd1 e LVAd2), Latossolo Vermelho distroférrico (LVdf) e Latossolo Vermelho distrófico (LVd)].

A irrigação foi realizada utilizando-se cinco frascos de vidro, que correspondiam às cinco frações da lâmina de irrigação: o primeiro e último frascos com água deonizada; os segundos, terceiros e quartos frascos tinham solução com os nutrientes, conforme os tratamentos. A água e as soluções foram pipetadas nos frascos com seu volume exato. As soluções com nutrientes foram preparadas previamente, mais concentradas para que na fração com o volume aplicado fosse obtida a concentração desejada por coluna. A aplicação das frações foi realizada de forma seqüencial, não havendo espaço de tempo entre uma fração e outra, e de tal forma a deixar uma lâmina constante com aproximadamente $1 \mathrm{~cm}$ de altura uniformemente sobre o solo. Ressalte-se que, sobre o solo, havia um disco de lã de vidro para evitar que a água se concentrasse num ponto da coluna e até mesmo alterasse a seção de infiltração, bem como para permitir que a solução se difundisse por ela e infiltrasse por todo o solo e não a partir de um único ponto, simulando uma irrigação por aspersão. Essa irrigação foi realizada em apenas um dia e, em cerca de 2 h, já tinha sido aplicado todo o volume de solução em todas as colunas. Após $2 \mathrm{~d}$ da aplicação da lâmina de irrigação, as colunas foram desmontadas. De imediato, do centro de cada um dos nove anéis superiores, retirou-se solo aproximadamente nos $5 \mathrm{~cm}$ 
Quadro 1. Caracterização física, química e mineralógica dos solos, peneirados por malha de $4 \mathrm{~mm}$

\begin{tabular}{|c|c|c|c|c|}
\hline Característica & LVAd1 & LVAd2 & LVdf & LVd \\
\hline \multicolumn{5}{|l|}{ Análise granulométrica $\left(\mathrm{kg} \mathrm{kg}^{-1}\right)$} \\
\hline $\begin{array}{l}\text { - } \operatorname{areia~grossa}^{(1)} \\
\text { - } \text { areia fina }^{(1)} \\
\text { - } \text { - }^{1+e^{(2)}}{ }^{(2)}\end{array}$ & $\begin{array}{l}0,25 \\
0,53 \\
0,04 \\
0,18\end{array}$ & $\begin{array}{l}0,27 \\
0,14 \\
0,04 \\
0,55\end{array}$ & $\begin{array}{l}0,21 \\
0,09 \\
0,15 \\
0,55\end{array}$ & $\begin{array}{l}0,06 \\
0,15 \\
0,11 \\
0,68\end{array}$ \\
\hline $\begin{array}{l}\text { Densidade }\left(\mathrm{kg} \mathrm{dm}^{-3}\right) \\
\quad \text {-do solo } \\
\text { - de partículas }\end{array}$ & $\begin{array}{l}1,24 \\
2,68\end{array}$ & $\begin{array}{l}1,03 \\
2,68\end{array}$ & $\begin{array}{l}0,96 \\
2,78\end{array}$ & $\begin{array}{l}0,88 \\
2,57\end{array}$ \\
\hline $\begin{array}{l}\text { Porosidade }\left(\mathrm{dm}^{3} \mathrm{dm}^{-3}\right) \\
\quad \text { - total } \\
\text { - macroporosidade } \\
\text { - microporosidade } \\
\text { - }{ }^{(7)}\end{array}$ & $\begin{array}{l}0,54 \\
0,37 \\
0,17\end{array}$ & $\begin{array}{l}0,62 \\
0,30 \\
0,32\end{array}$ & $\begin{array}{l}0,65 \\
0,32 \\
0,33\end{array}$ & $\begin{array}{l}0,66 \\
0,26 \\
0,40\end{array}$ \\
\hline $\mathrm{N}-\mathrm{NH}_{4}^{+}\left(\mathrm{mg} \mathrm{dm}^{-3}\right)^{(8)}$ & 4,18 & 5,31 & 5,65 & 5,23 \\
\hline $\mathrm{N}-\mathrm{NO}_{3}^{-} \quad\left(\mathrm{mg} \mathrm{dm}^{-3}\right)^{(9)}$ & 5,11 & 6,68 & 18,35 & 12,26 \\
\hline $\mathrm{K}\left(\mathrm{mg} \mathrm{dm}^{-3}\right)^{(10)}$ & 11,4 & 41,0 & 40,0 & 67,0 \\
\hline $\left.\mathrm{P}(\mathrm{mg} \mathrm{dm})^{-3}\right)^{(11)}$ & 1,10 & 2,40 & 1,70 & 4,40 \\
\hline $\mathrm{Ca}^{2+}\left(\mathrm{cmol}_{\mathrm{c}} \mathrm{dm}^{-3}\right)^{(12)}$ & 0,01 & 0,03 & 0,39 & 0,56 \\
\hline $\mathrm{Mg}^{2+}\left(\mathrm{cmol}_{\mathrm{c}} \mathrm{dm}^{-3}\right)^{(12)}$ & 0,00 & 0,06 & 0,35 & 0,27 \\
\hline $\mathrm{Al}^{3+} \quad\left(\mathrm{cmol}_{\mathrm{c}} \mathrm{dm}^{-3}\right)^{(12)}$ & 0,17 & 2,20 & 1,20 & 1,00 \\
\hline Carbono orgânico $\left(\mathrm{dag} \mathrm{kg}^{-1}\right)^{(13)}$ & 2,17 & 2,44 & 3,57 & 4,36 \\
\hline pH em água $(1: 2,5)$ & 4,95 & 4,97 & 4,44 & 4,80 \\
\hline $\mathrm{pH}$ em KCl $\left.1 \mathrm{~mol} \mathrm{~L}^{-1}\right)(1: 2,5)$ & 3,97 & 4,23 & 4,14 & 3,98 \\
\hline$\Delta \mathrm{pH}$ & $-0,98$ & $-0,74$ & $-0,66$ & $-0,46$ \\
\hline P remanescente $\left(\mathrm{mg} \mathrm{L}^{-1}\right)^{(14)}$ & 49,49 & 8,29 & 6,34 & 12,17 \\
\hline \multirow{2}{*}{$\begin{array}{l}\text { Mineralogia da fração argila }{ }^{(15)} \\
\text { (principais minerais, em proporção decrescente) }\end{array}$} & $\mathrm{Ka}$ & $\mathrm{Ka}$ & $\mathrm{Ka}$ & $\mathrm{Ka}$ \\
\hline & $\begin{array}{c}\mathrm{Gb} \\
\mathrm{Il}\end{array}$ & $\begin{array}{c}\mathrm{Gb} \\
\mathrm{VHE}\end{array}$ & $\begin{array}{l}\mathrm{Gb} \\
\mathrm{Hm}\end{array}$ & $\begin{array}{c}\mathrm{Gt} \\
\mathrm{Hm}\end{array}$ \\
\hline
\end{tabular}

${ }^{(1)}$ Por peneiramento (Ruiz, 2005). ${ }^{(2)}$ Método da pipeta (Ruiz, 2005). ${ }^{(3)}$ Método da proveta (Embrapa, 1997). ${ }^{(4)}$ Método do balão volumétrico (Embrapa, 1997). ${ }^{(5)}$ Porosidade total $=1$ - (densidade do solo/densidade de partículas). ${ }^{(6)}$ Água retida entre 0 e -6 kPa. (Ruiz, 2004) ${ }^{(7)}$ Água retida a $-6 \mathrm{kPa}$ (Ruiz, 2004). ${ }^{(8)}$ Dosagem com solução de salicilato de sódio (Kempers \& Zewers, 1986). ${ }^{(9)}$ Dosagem com solução de salicilato de sódio (Yang et al., 1998). ${ }^{(10)}$ Extrator Mehlich-1 (Defelipo \& Ribeiro, 1997). ${ }^{(11)}$ Extrator Mehlich-1 (Braga \& Defelipo, 1974). ${ }^{(12)}$ Extrator KCl $1 \mathrm{~mol} \mathrm{~L}^{-1}$ (Embrapa, 1997). ${ }^{(13)}$ Oxidação com dicromato de potássio e titulação com sulfato ferroso amoniacal (Yeomans \& Bremner, 1988). (14) Alvarez V. et al. (2000). (15) Gb: gibbsita, Gt: goethita, Hm: hematita, Ka: caulinita, Il: ilita, VHE: vermiculita com hidróxido-entrecamadas. Referências para caracterização mineralógica: Amaral, 2000 (LVAd2); Donagemma, 2000 (LVdf); Santos Neto, 2003 (LVAd1); e Araújo, 1997 (LVd). LVAd1: Latossolo Vermelho-Amarelo distrófico textura média; LVAd2: Latossolo Vermelho-Amarelo distrófico textura argilosa; LVdf: Latossolo Vermelho distroférrico textura argilosa; LVd: Latossolo Vermelho distrófico textura muito argilosa.

Quadro 2. Quantidade de reagente aplicada nas colunas de $2,4 \mathrm{dm}^{3}$ de solo

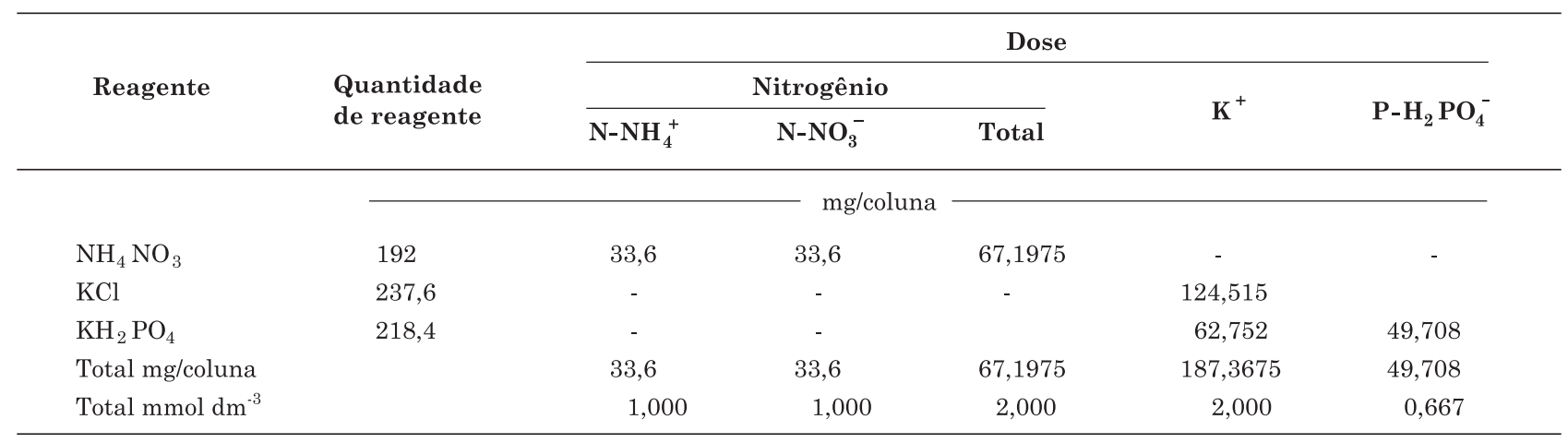


centrais, ficando cerca de $1 \mathrm{~cm}$ acima e abaixo e $1 \mathrm{~cm}$ afastado da parede, fora da amostragem. Subamostras foram utilizadas para a determinação colorimétrica do teor de $\mathrm{N}-\mathrm{NH}_{4}{ }^{+}$(Kempers \& Zwers, 1986) e do teor de $\mathrm{N}-\mathrm{NO}_{3}{ }^{-}$(Yang et al. 1998), após extração com solução de $\mathrm{KCl} 1 \mathrm{~mol} \mathrm{~L}^{-1}$, e determinação do teor de $\mathrm{K}^{+}$e do teor de $\mathrm{P}-\mathrm{H}_{2} \mathrm{PO}_{4}^{-}$, extraídos por Mehlich-1, dosados por fotometria de chama (Defelipo \& Ribeiro, 1997) e por colorimetria (Braga \& Defelipo, 1974), respectivamente.

Considerando os teores dos nutrientes determinados em amostras de cada anel, representou-se graficamente a distribuição nas colunas. Relacionando esses valores com a profundidade média (3,5 até $59,5 \mathrm{~cm}$ ), foi caracterizada a distribuição dos nutrientes nas colunas de solo. Posteriormente, estabeleceu-se, para cada solo e cada tratamento, a profundidade média do maior teor e seu valor numérico (média de três repetições). A profundidade em que se atingiu o maior teor dos nutrientes foi analisada estatisticamente. Na análise de variância, os graus de liberdade para tratamentos foram desdobrados em contrastes ortogonais. Foram calculados os contrastes médios $(\overline{\mathrm{C}})$, pela expressão $\overline{\mathrm{C}}=\frac{\sum \mathrm{c}_{\mathrm{i}} \overline{\mathrm{y}}_{\mathrm{i}}}{\sum\left|\mathrm{c}_{\mathrm{i}}\right| / 2}$, em que $\mathrm{c}_{\mathrm{i}}$ é o coeficiente ortogonal e $\bar{y}_{i}$ é a média das determinações (Alvarez V. \& Alvarez, 2006)

\section{RESULTADOS E DISCUSSÃO}

A distribuição de $\mathrm{NO}_{3}{ }^{-}$, após a aplicação da dose de nutrientes integral ou fracionada na fração da lâmina de irrigação, como no caso do tratamento $\mathrm{F}_{2} \mathrm{D}_{1 / 2} \mathrm{~F}_{4} \mathrm{D}_{1 / 2}$, que recebeu dois aportes de nutrientes, é mostrada nas figuras 1 e 2. A aplicação da quantidade de $33,6 \mathrm{mg}$ de $\mathrm{NO}_{3}{ }^{-}$em cada coluna de solo contribuiu com o incremento do teor do nutriente no solo, como era de se esperar. Observou-se que a distribuição dos nutrientes, ao longo da coluna, foi influenciada pelo momento em que se aplicou a dose integral dos nutrientes, ou seja, pela fração da lâmina de irrigação em que foi aplicada a dose desse ânion. Assim, a maior lâmina de água aplicada posteriormente à dose de nutrientes justifica a localização do maior teor de $\mathrm{NO}_{3}{ }^{-}$ em maior profundidade no tratamento $\mathrm{F}_{2} \mathrm{D}$, em posição intermediária no $\mathrm{F}_{3} \mathrm{D}$ e mais superficialmente no $\mathrm{F}_{4} \mathrm{D}$. Com a aplicação da dose em duas frações, a maior lâmina posterior à dose de nutrientes também levou à maior movimentação do $\mathrm{NO}_{3}{ }^{-}$na coluna, como mostrado para os tratamentos $\mathrm{F}_{2} \mathrm{D}_{1 / 2} \mathrm{~F}_{3} \mathrm{D}_{1 / 2}$ e $\mathrm{F}_{3} \mathrm{D}_{1 / 2}$ $\mathrm{F}_{4} \mathrm{D}_{1 / 2}$ (Figuras 1 e 2 ).

A distribuição de $\mathrm{NO}_{3}{ }^{-}$para o tratamento $\mathrm{F}_{2} \mathrm{D}_{1 / 2}$ $\mathrm{F}_{4} \mathrm{D}_{1 / 2}$, que, na prática, possivelmente não seria utilizado em fertirrigação, mostra resposta à aplicação da dose de nutrientes fracionada em duas, evidenciando dois pontos de maior teor em todos os solos estudados (Figuras 1 e 2). Quando a dose foi subdividida em três frações da lâmina, o $\mathrm{NO}_{3}{ }^{-}$ficou localizado em posições mais superficiais na coluna (Figuras 1 e 2). Observa-se, então, que o fracionamento da dose de $\mathrm{NO}_{3}{ }^{-}$, comparado com a aplicação da dose integral na fração da lâmina de irrigação, favorece a retenção do nutriente na fase sólida do solo, retardando seu deslocamento. Tal fato, provavelmente, se deve à menor concentração do elemento, o que favorece a adsorção pela fase sólida.

A aplicação da dose integral, ou seja, mais concentrada, reduziria a interação do íon com os sítios de troca, comparado com o fracionamento da dose, favorecendo, dessa forma, o movimento em maior profundidade. A resposta da distribuição do $\mathrm{NO}_{3}{ }^{-}$aos tratamentos utilizados permite indicar que, quando aplicado em dose integral ou fracionada seqüencialmente uma fração da lâmina de irrigação somente com água $\left(\mathrm{F}_{2} \mathrm{D}, \mathrm{F}_{3} \mathrm{D}, \mathrm{F}_{4} \mathrm{D}, \mathrm{F}_{2} \mathrm{D}_{1 / 2} \mathrm{~F}_{3} \mathrm{D}_{1 / 2}, \mathrm{~F}_{3} \mathrm{D}_{1 / 2} \mathrm{~F}_{4} \mathrm{D}_{1 / 2}\right.$ e $\mathrm{F}_{2} \mathrm{D}_{1 / 3}$ $\mathrm{F}_{3} \mathrm{D}_{1 / 3} \mathrm{~F}_{4} \mathrm{D}_{1 / 3}$ ), localiza-se em maior profundidade com a maior concentração na fração da lâmina e com a maior lâmina de água posterior à sua aplicação (Figuras 1 e 2).

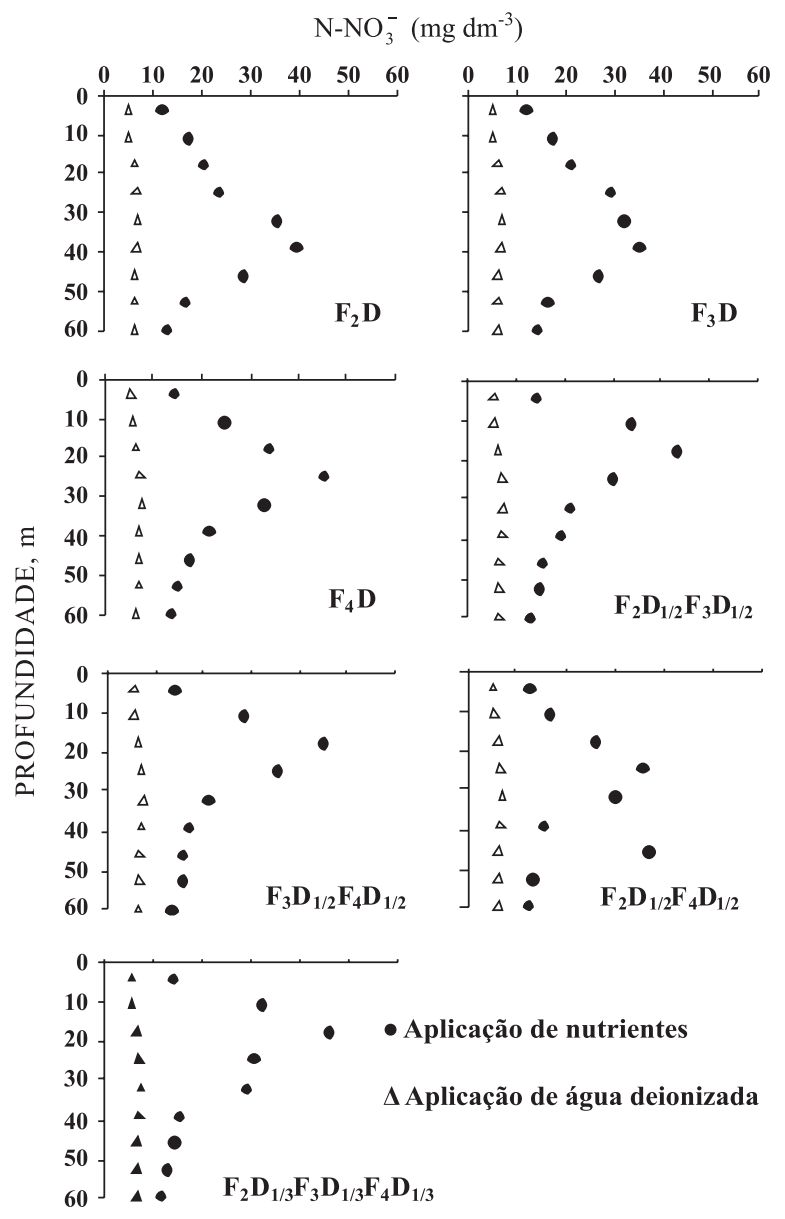

Figura 1. Teores de nitrato ao longo de colunas com amostras do LVAd2, considerando a fração da lâmina de irrigação (F) em que o nutriente foi aplicado em dose integral (D) ou fracionado em duas $\left(D_{1 / 2}\right)$ ou em três vezes $\left(D_{1 / 3}\right)$. 
$\mathrm{N}-\mathrm{NO}_{3}^{-}\left(\mathrm{mg} \mathrm{dm}^{-3}\right)$

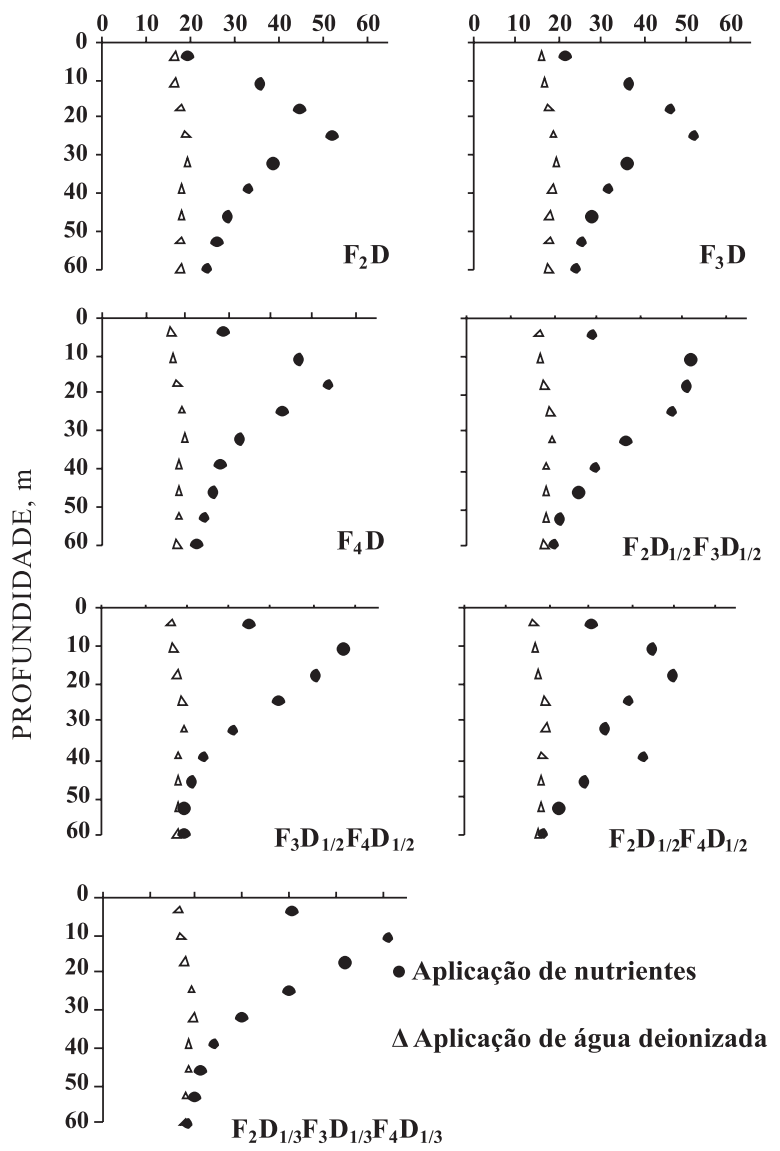

Figura 2. Teores de nitrato ao longo de colunas com amostras do LVdf, considerando a fração da lâmina de irrigação (F) em que o nutriente foi aplicado em dose integral (D) ou fracionado em duas $\left(D_{1 / 2}\right)$ ou em três vezes $\left(D_{1 / 3}\right)$.

Comparando a distribuição do $\mathrm{NO}_{3}{ }^{-}$ao longo da coluna de solo entre o LVAd2 e o LVdf, observou-se que, no LVdf (mais oxídico e com mesma proporção de argila)(Quadro 1) o $\mathrm{NO}_{3}{ }^{-}$aprofundou menos na coluna de solo para um mesmo tratamento, como indicado pela menor profundidade do maior teor de $\mathrm{NO}_{3}{ }^{-}$ (Figuras 1 e 2). Esse resultado era esperado, uma vez que esse solo em $\mathrm{pH}$ natural possui uma quantidade de carga positiva maior do que o LVAd2, que é caulinítico. Dessa forma, a carga positiva atrai o $\mathrm{NO}_{3}^{-}$e este fica mais retido na fase sólida do solo, retardando seu movimento em relação ao LVAd2. Essa maior proporção de carga positiva no LVdf em relação ao LVAd2 é indicada de forma indireta pelos valores de $\mathrm{DpH}$, pois o LVdf apresenta $\Delta \mathrm{pH}-0,66$ e o LVAd -0,74 (Quadro 1), ou seja, é menos eletronegativo, com maior proporção de carga positiva para retardar o movimento do $\mathrm{NO}_{3}{ }^{-}$e menor proporção de carga negativa para repelir o $\mathrm{NO}_{3}{ }^{-}$.

A reposta da distribuição de $\mathrm{NH}_{4}{ }^{+}$aos tratamentos foi semelhante à do $\mathrm{NO}_{3}{ }^{-}$. Nesses mesmos dois solos, o $\mathrm{NH}_{4}{ }^{+}$movimentou-se para maior profundidade do LVdf em relação ao LVAd2, e a explicação é inversa à do $\mathrm{NO}_{3}{ }^{-}$. Neste caso, a maior proporção de carga positiva levou a repelir o $\mathrm{NH}_{4}^{+}$, ficando mais na solução do solo passível de ser transportado, movimentando-se em maior profundidade do que no LVAd2, evidenciado pela maior profundidade do maior teor de $\mathrm{NO}_{3}{ }^{-}$(Figuras 1 e 2). Observou-se também que o $\mathrm{NH}_{4}{ }^{+}$é bastante móvel nos solos como $\mathrm{NO}_{3}{ }^{-}$, uma vez que, em geral, é retido somente por atração eletrostática e fica em equilíbrio com a solução, ou seja, os solos têm em geral baixa capacidade de fixação do $\mathrm{NH}_{4}{ }^{+}$(Wang \& Alva, 2000), sobretudo solos arenosos e de textura média, com predomínio de argilas 1:1. À medida que a sua concentração reduz-se na solução, sai da fase sólida e vai para a solução. Oliveira et al. (2004) também observaram menor retardamento no movimento do $\mathrm{NH}_{4}{ }^{+}$em solo com menor proporção de argila e maior proporção de areia.

A distribuição do $\mathrm{K}^{+}$foi diferenciada, quando confrontada com a do $\mathrm{NH}_{4}{ }^{+}$e do $\mathrm{NO}_{3}{ }^{-}$, como indicado nas figuras 3 e 4 .

$\mathrm{O}$ ponto de maior teor de $\mathrm{K}^{+}$localizou-se no anel superficial em todos os tratamentos que receberam a dose de nutrientes, indicando menor mobilidade (Figuras 3 e 4). Além disso, verificou-se que o deslocamento do $\mathrm{K}^{+}$em profundidade foi menor do que o do $\mathrm{NH}_{4}{ }^{+}$e $\mathrm{NO}_{3}{ }^{-}$, diferindo dos dois últimos, em que o nutriente atingia um ponto de maior teor em profundidade e depois decrescia.

A menor mobilidade do $\mathrm{K}^{+}$em relação ao $\mathrm{NH}_{4}{ }^{+}$foi observada também por Oliveira et al. (2003), trabalhando com Latossolos. Também Silva (2004) verificou esse comportamento, no confronto com $\mathrm{NH}_{4}{ }^{+}$ e $\mathrm{NO}_{3}{ }^{-}$, em pesquisa na qual utilizou os mesmos solos aqui estudados.

A menor mobilidade do $\mathrm{K}^{+}$com relação ao $\mathrm{NH}_{4}{ }^{+}$, ambos cátions monovalentes, pode ser atribuída ao menor raio iônico hidratado do primeiro. A lei de Coulomb mostra que a força de atração entre partículas de carga de sinal oposto, com os mesmos valores de carga, é inversamente proporcional ao quadrado da distância. Assim, o menor raio iônico hidratado indica menor distância e maior atração do $\mathrm{K}^{+}$pelo complexo de troca catiônica do solo, quando comparado ao amônio (Griffioen, 2001). Essa menor mobilidade ocorreu mesmo com uma dose bem maior de $\mathrm{K}^{+}$frente a de $\mathrm{NH}_{4}{ }^{+}$(187,37 e 33,6 mg/coluna, respectivamente).

Considerando o $\mathrm{NO}_{3}{ }^{-}$, a menor mobilidade do $\mathrm{K}^{+}$ está relacionada ao caráter aniônico do primeiro, que leva à sua repulsão pelas cargas negativas predominantes no solo. Todos os solos estudados apresentaram $\Delta \mathrm{pH}$ negativo, ou seja, com predomínio de cargas negativas (Quadro 1).

Para o $\mathrm{H}_{2} \mathrm{PO}_{4}^{-}$, não houve distribuição mesmo em profundidade na coluna. Nas condições experimentais, em que a água aplicada foi inferior a meio volume de 
poros, esse comportamento do $\mathrm{H}_{2} \mathrm{PO}_{4}{ }^{-}$era esperado. Em trabalho com alguns dos solos utilizados neste ensaio, Oliveira et al. (2004) determinaram fatores de retardamento para $\mathrm{O}_{2} \mathrm{PO}_{4}^{-}$na faixa de 13 a 20 volumes de poros, o que mostra a baixa mobilidade deste elemento no solo. Observou-se que o $\mathrm{H}_{2} \mathrm{PO}_{4}{ }^{-}$ ficou localizado na superfície, o que restringiria sua absorção restrita às raízes na camada mais superficial. Assim, a fertirrigação com $\mathrm{H}_{2} \mathrm{PO}_{4}{ }^{-}$não seria recomendada, sendo adequado incorporá-lo na profundidade do solo de maior densidade de raízes.

A partir da caracterização da distribuição dos nutrientes, determinou-se a profundidade do maior teor. Avaliando os resultados da profundidade de maior teor dos nutrientes (Quadro 3) e a comparação do efeito dos tratamentos na profundidade do maior teor dos nutrientes entre os solos (Quadro 4) e dentro de cada solo (Quadro 5), verificou-se que, com a aplicação do nutriente, a distribuição foi afetada pela fração da lâmina de irrigação à qual se acrescentou o fertilizante em dose única. Assim, a maior lâmina de água aplicada posteriormente à dose de nutrientes justifica o maior teor de $\mathrm{NH}_{4}{ }^{+}$na maior profundidade. $\mathrm{O}$ fracionamento da dose de $\mathrm{NH}_{4}{ }^{+}$, comparado com a

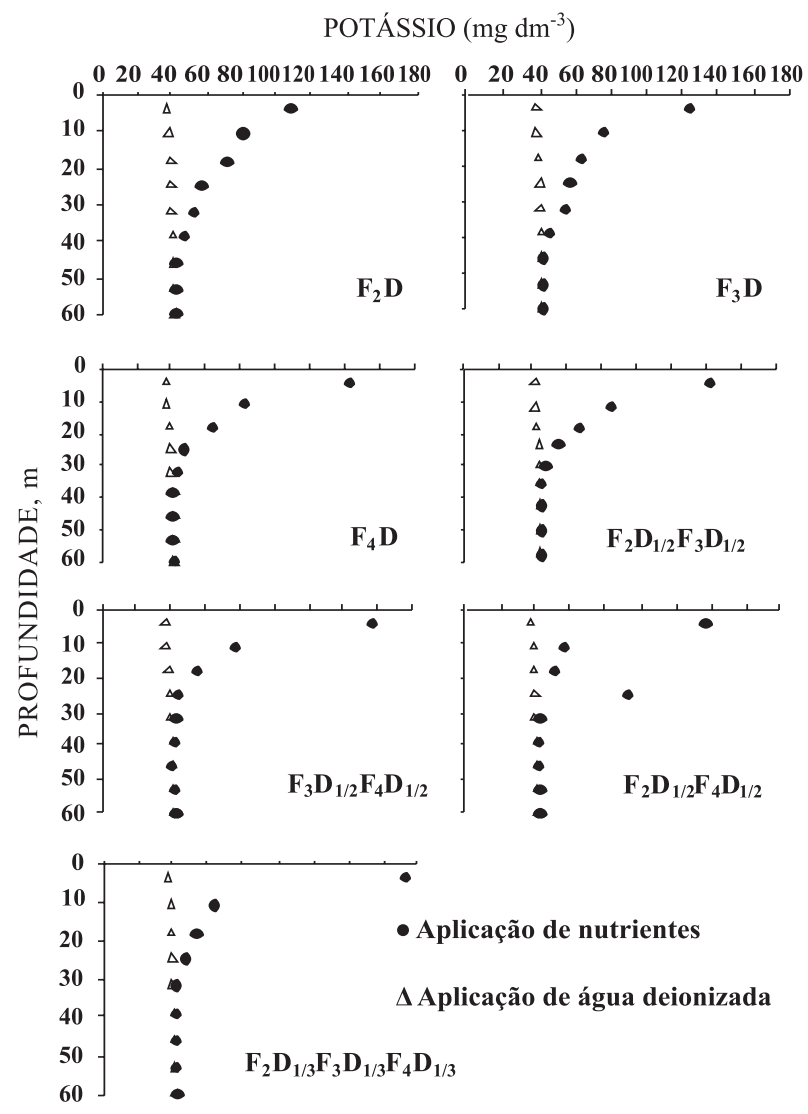

Figura 3. Teores de potássio ao longo de colunas com amostras do LVAd2, considerando a fração da lâmina de irrigação (F) em que o nutriente foi aplicado em dose integral (D) ou fracionado em duas $\left(D_{1 / 2}\right)$ ou em três vezes $\left(D_{1 / 3}\right)$.
POTÁSSIO $\left(\mathrm{mg} \mathrm{dm}^{-3}\right)$

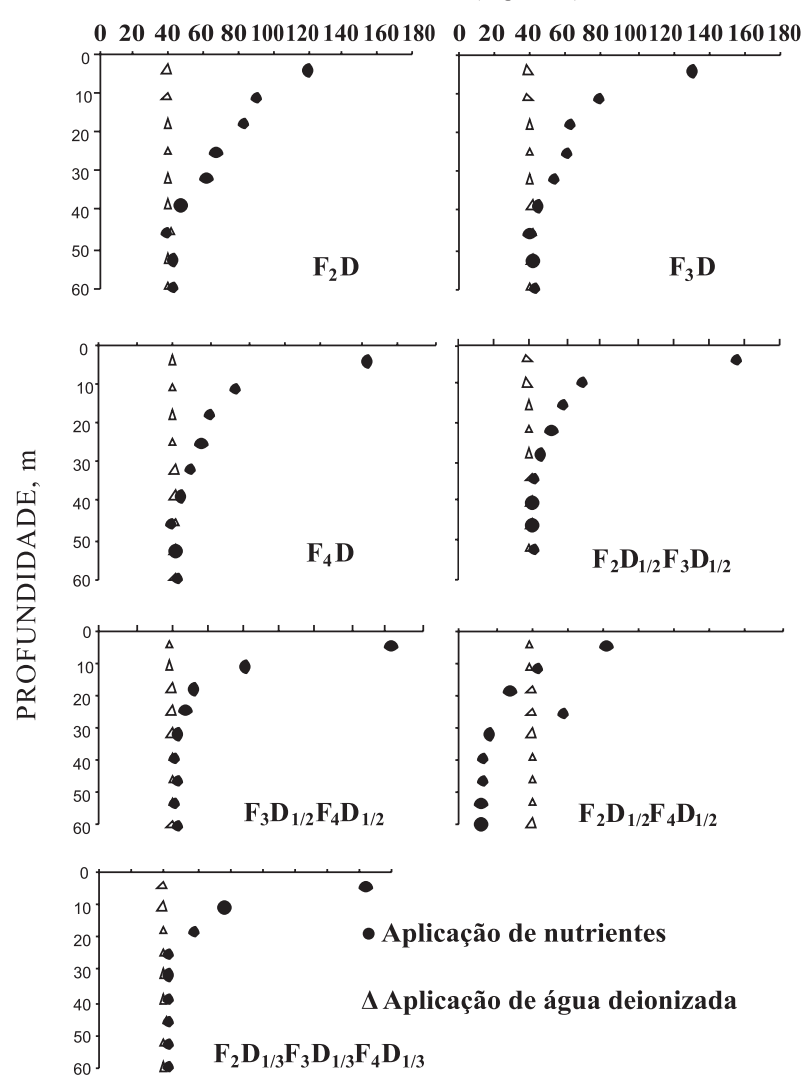

Figura 4. Teores de potássio ao longo de colunas com amostras do LVdf, considerando a fração da lâmina de irrigação (F) em que o nutriente foi aplicado em dose integral (D) ou fracionado em duas $\left(D_{1 / 2}\right)$ ou em três vezes $\left(D_{1 / 3}\right)$.

aplicação da dose integral na fração da lâmina de irrigação, favoreceu a retenção do nutriente na fase sólida do solo, retardando seu deslocamento. $\mathrm{O} \mathrm{NO}_{3}{ }^{-}$ apresentou resposta semelhante à do $\mathrm{NH}_{4}{ }^{+}$, evidenciando pontos de maior teor em diferentes profundidades. Comparando o LVdf e o LVAd2, que apresentam a mesma proporção de argila, observouse que o $\mathrm{NO}_{3}^{-}$movimentou-se menos no $\mathrm{LVdf}$, evidenciado pelo ponto de maior teor em menor profundidade do que no LVAd2. Isso está relacionado novamente ao fato de esse solo ser menos eletronegativo que o LVAd2; assim, menor concentração de $\mathrm{NO}_{3}{ }^{-}$é repelida, e o nutriente fica mais retido na fase sólida do solo, retardando seu movimento. Esse resultado sugere que, para uma mesma dose desse nutriente e nas demais condições semelhantes, esse solo teria menor risco de contaminação de água subterrânea por $\mathrm{NO}_{3}{ }^{-}$do que o LVAd2. Além disso, considerando essa capacidade diferencial de reter os nutrientes e a diferença de risco de contaminação de água subterrânea, as recomendações de doses de nutrientes em fertirrigação deveriam considerar também o tipo de solo e não somente o tipo de cultura, como é usual hoje. 
Considerando todos os solos estudados, observa-se a seguinte ordem de risco de contaminação de água subterrânea por $\mathrm{NO}_{3}^{-}:$LVAd1 $>\operatorname{LVAd} 2>\mathrm{LVdf}>\mathrm{LVd}$, como indicado pelos resultados da profundidade de maior teor de $\mathrm{NO}_{3}{ }^{-}$nesses solos (Quadros 3 e 4). Esse resultado está ligado a diferenças na proporção de argila e na mineralogia dessa fração (Quadro 1). O LVAd1 tem textura média e menor proporção de argila para reter o $\mathrm{NO}_{3}^{-}$; já os solos LVAd2 e LVdf são argilosos com mesma proporção de argila, só que o LVdf é mais oxídico e apresenta maior proporção de cargas positivas para reter o $\mathrm{NO}_{3}{ }^{-}$; dessa forma, retarda mais seu movimento e apresenta menor risco de contaminação da água subterrânea. O LVd é de textura muito argilosa e tem maior proporção de cargas positivas para reter o $\mathrm{NO}_{3}^{-}$, embora predomine caulinita na sua fração argila. Esse solo apresenta gibbsita, o que favorece a formação de carga positiva e retarda o movimento do $\mathrm{NO}_{3}{ }^{-}$diminuindo o risco da contaminação de água subterrânea. Silva (2004), tra- balhando com os mesmos solos, observou maiores perdas de $\mathrm{NO}_{3}{ }^{-}$no lixiviado na mesma ordem do risco de contaminação de água subterrânea deste estudo.

A resposta do $\mathrm{K}^{+}$foi diferenciada quando confrontada à do $\mathrm{NH}_{4}{ }^{+}$e do $\mathrm{NO}_{3}{ }^{-}$. $\mathrm{O} \mathrm{K}^{+}$apresentou ponto de maior teor no anel superficial em todos os tratamentos que receberam dose do nutriente, indicando menor mobilidade. Esse resultado indica o cuidado que se deve ter na fertirrigação, principalmente quando há aplicações continuadas de doses elevadas de $\mathrm{K}^{+}$. Dependendo também do volume de água aplicado, pode haver a salinização da superfície do solo, pois esse nutriente vai se concentrando superficialmente, mesmo em Latossolos bem drenados, como os estudados, ou seja, com elevada velocidade de infiltração de água em condições naturais.

Para o $\mathrm{H}_{2} \mathrm{PO}_{4}{ }^{-}$não houve movimentação ao longo da coluna. Toda a dose de nutriente aplicada ficou concentrada no primeiro anel. Esse resultado está

Quadro 3. Profundidade do maior teor (Prof) e valores correspondentes (MT) de amônio, nitrato, potássio e fósforo na coluna, considerando o solo e a fração da lâmina de irrigação em que o nutriente foi aplicado (F) em dose integral (D) ou fracionado em duas $\left(D_{1 / 2}\right)$ ou em três vezes $\left(D_{1 / 3}\right)$

\begin{tabular}{|c|c|c|c|c|c|c|c|c|c|}
\hline \multirow{2}{*}{ Solo } & \multirow{2}{*}{ Tratamento } & \multicolumn{2}{|c|}{$\mathbf{N}-\mathrm{NH}_{4}^{+}$} & \multicolumn{2}{|c|}{$\mathrm{N}-\mathrm{NO}_{3}^{-}$} & \multicolumn{2}{|c|}{ Potássio } & \multicolumn{2}{|c|}{ Fósforo } \\
\hline & & Prof. & MT & Prof. & MT & Prof. & MT & Prof. & MT \\
\hline \multirow{8}{*}{ LVAd1 } & & $\mathrm{cm}$ & $\mathrm{mg} \mathrm{dm}{ }^{-3}$ & $\mathrm{~cm}$ & $\mathrm{mg} \mathrm{dm}{ }^{-3}$ & $\mathrm{~cm}$ & $\mathrm{mg} \mathrm{dm}{ }^{-3}$ & $\mathrm{~cm}$ & $\mathrm{mg} \mathrm{dm}{ }^{-3}$ \\
\hline & Água & 45,5 & 5,07 & 31,5 & 6,57 & 40,8 & 11,69 & 10,5 & 1,30 \\
\hline & $\mathrm{F}_{2} \mathrm{D}$ & 45,5 & 10,62 & 43,2 & 34,87 & 3,5 & 57,57 & 3,5 & 41,40 \\
\hline & $\mathrm{F}_{3} \mathrm{D}$ & 38,5 & 10,54 & 38,5 & 35,40 & 3,5 & 82,12 & 3,5 & 41,51 \\
\hline & $\mathrm{F}_{4} \mathrm{D}$ & 31,5 & 11,22 & 31,5 & 35,57 & 3,5 & 92,31 & 3,5 & 42,36 \\
\hline & $\mathrm{F}_{2} \mathrm{D}_{1 / 2} \mathrm{~F}_{3} \mathrm{D}_{1 / 2}$ & 38,5 & 12,33 & 24,5 & 37,40 & 3,5 & 96,27 & 3,5 & 41,51 \\
\hline & $\mathrm{F}_{3} \mathrm{D}_{1 / 2} \mathrm{~F}_{4} \mathrm{D}_{1 / 2}$ & 31,5 & 11,77 & 17,5 & 41,28 & 3,5 & 105,18 & 3,5 & 40,87 \\
\hline & $\mathrm{F}_{2} \mathrm{D}_{1 / 3} \mathrm{~F}_{3} \mathrm{D}_{1 / 3} \mathrm{~F}_{4} \mathrm{D}_{1 / 3}$ & 24,5 & 12,57 & 17,5 & 44,56 & 3,5 & 116,57 & 3,5 & 41,13 \\
\hline Média & & 36,5 & 10,59 & 29,2 & 33,67 & 8,9 & 80,24 & 4,5 & 35,72 \\
\hline \multirow[t]{7}{*}{ LVAd2 } & Água & 31,5 & 5,46 & 33,8 & 7,24 & 59,5 & 41,54 & 45,5 & 2,34 \\
\hline & $\mathrm{F}_{2} \mathrm{D}$ & 31,5 & 11,84 & 38,5 & 39,45 & 3,5 & 106,8 & 3,5 & 34,55 \\
\hline & $\mathrm{F}_{3} \mathrm{D}$ & 24,5 & 11,16 & 31,5 & 43,46 & 3,5 & 123,35 & 3,5 & 35,42 \\
\hline & $\mathrm{F}_{4} \mathrm{D}$ & 24,5 & 12,39 & 24,5 & 43,52 & 3,5 & 135,25 & 3,5 & 34,17 \\
\hline & $\mathrm{F}_{2} \mathrm{D}_{1 / 2} \mathrm{~F}_{3} \mathrm{D}_{1 / 2}$ & 24,5 & 13,11 & 17,5 & 43,25 & 3,5 & 142,46 & 3,5 & 35,53 \\
\hline & $\mathrm{F}_{3} \mathrm{D}_{1 / 2} \mathrm{~F}_{4} \mathrm{D}_{1 / 2}$ & 17,5 & 13,02 & 17,5 & 44,78 & 3,5 & 156,73 & 3,5 & 35,65 \\
\hline & $\mathrm{F}_{2} \mathrm{D}_{1 / 3} \mathrm{~F}_{3} \mathrm{D}_{1 / 3} \mathrm{~F}_{4} \mathrm{D}_{1 / 3}$ & 17,5 & 15,10 & 17,5 & 45,45 & 3,5 & 172,04 & 3,5 & 35,60 \\
\hline Média & & 24,5 & 11,72 & 25,8 & 38,17 & 11,5 & 125,45 & 9,6 & 30,47 \\
\hline \multirow[t]{7}{*}{$\mathrm{LVdf}$} & Água & 38,5 & 6,35 & 31,5 & 19,41 & 47,8 & 40,66 & 24,5 & 1,73 \\
\hline & $\mathrm{F}_{2} \mathrm{D}$ & 38,5 & 13,45 & 24,5 & 51,68 & 3,5 & 120,35 & 3,5 & 19,69 \\
\hline & $\mathrm{F}_{3} \mathrm{D}$ & 31,5 & 14,01 & 22,2 & 50,03 & 3,5 & 130,07 & 3,5 & 20,24 \\
\hline & $\mathrm{F}_{4} \mathrm{D}$ & 31,5 & 13,84 & 17,5 & 54,22 & 3,5 & 142,90 & 3,5 & 20,66 \\
\hline & $\mathrm{F}_{2} \mathrm{D}_{1 / 2} \mathrm{~F}_{3} \mathrm{D}_{1 / 2}$ & 24,5 & 14,43 & 10,5 & 51,67 & 3,5 & 153,86 & 3,5 & 19,88 \\
\hline & $\mathrm{F}_{3} \mathrm{D}_{1 / 2} \mathrm{~F}_{4} \mathrm{D}_{1 / 2}$ & 17,5 & 14,40 & 10,5 & 56,59 & 3,5 & 161,21 & 3,5 & 19,81 \\
\hline & $\mathrm{F}_{2} \mathrm{D}_{1 / 3} \mathrm{~F}_{3} \mathrm{D}_{1 / 3} \mathrm{~F}_{4} \mathrm{D}_{1 / 3}$ & 24,5 & 16,36 & 10,5 & 60,65 & 3,5 & 162,47 & 3,5 & 20,34 \\
\hline Média & & 29,5 & 13,26 & 18,2 & 49,18 & 9,8 & 130,22 & 6,5 & 17,49 \\
\hline \multirow[t]{7}{*}{ LVd } & Água & 38,5 & 5,64 & 33,8 & 12,53 & 43,2 & 66,90 & 43,2 & 4,49 \\
\hline & $\mathrm{F}_{2} \mathrm{D}$ & 31,5 & 14,49 & 38,5 & 49,11 & 3,5 & 141,11 & 3,5 & 29,99 \\
\hline & $\mathrm{F}_{3} \mathrm{D}$ & 24,5 & 13,70 & 31,5 & 49,42 & 3,5 & 147,44 & 3,5 & 30,31 \\
\hline & $\mathrm{F}_{4} \mathrm{D}$ & 24,5 & 14,35 & 24,5 & 44,87 & 3,5 & 154,98 & 3,5 & 30,39 \\
\hline & $\mathrm{F}_{2} \mathrm{D}_{1 / 2} \mathrm{~F}_{3} \mathrm{D}_{1 / 2}$ & 17,5 & 15,15 & 17,5 & 48,58 & 3,5 & 164,27 & 3,5 & 30,28 \\
\hline & $\mathrm{F}_{3} \mathrm{D}_{1 / 2} \mathrm{~F}_{4} \mathrm{D}_{1 / 2}$ & 24,5 & 15,71 & 17,5 & 57,23 & 3,5 & 175,58 & 3,5 & 31,00 \\
\hline & $\mathrm{F}_{2} \mathrm{D}_{1 / 3} \mathrm{~F}_{3} \mathrm{D}_{1 / 3} \mathrm{~F}_{4} \mathrm{D}_{1 / 3}$ & 10,5 & 15,65 & 17,5 & 59,36 & 3,5 & 184,65 & 3,5 & 31,52 \\
\hline Média & & 24,5 & 13,52 & 25,8 & 45,88 & 9,2 & 147,84 & 9,2 & 26,85 \\
\hline
\end{tabular}


relacionado à rápida passagem do $\mathrm{P}$ lábil a não-lábil (Novais \& Smyth, 1999), levando à baixa concentração da solução para ser transportada, não aprofundando

Quadro 4. Contrastes médios comparando a profundidade do maior teor de amônio, nitrato, potássio e fósforo, considerando os solos que apresentaram homogeneidade de variâncias

\begin{tabular}{|c|c|c|}
\hline Nutriente & Contraste & Valor \\
\hline & & $\mathrm{cm}$ \\
\hline $\mathrm{N}-\mathrm{NH}_{4}^{+}$ & $\begin{array}{l}3 \text { LVAd1 - (LVAd2 + LVdf + LVd }) \\
2 \text { LVAd2 - (LVdf + LVd }) \\
\text { LVdf - LVd }\end{array}$ & $\begin{array}{r}9,9^{* *} \\
-2,2^{\text {** }} \\
4,4^{\text {** }}\end{array}$ \\
\hline $\mathrm{N}-\mathrm{NO}_{3}^{-}$ & $\begin{array}{l}3 \text { LVAd1 }-(\text { LVAd2 + LVdf + LVd }) \\
2 \text { LVAd2 - (LVdf + LVd }) \\
\text { LVdf - LVd }\end{array}$ & $\begin{array}{l}3,1^{* *} \\
5,6^{* *} \\
-9,3^{* *}\end{array}$ \\
\hline Potássio & $\begin{array}{l}2 \operatorname{LVAd} 2-(\operatorname{LVdf}+\mathrm{LVd}) \\
\text { LVdf - LVd }\end{array}$ & $\begin{array}{r}-0,6 \\
0,5\end{array}$ \\
\hline Fósforo & LVAd1 - LVAd2 & $-4,4$ \\
\hline
\end{tabular}

**: Significativo a $1 \%$ pelo teste $\mathrm{F}$. na coluna, e também à baixa quantidade de água aplicada, inferior a meio volume de poros. A mobilidade, determinada para os quatro nutrientes em estudo, para os solos LVAd1, LVAd2 e LVd foi: $\mathrm{NO}_{3}{ }^{-}>\mathrm{NH}_{4}{ }^{+}>\mathrm{K}^{+}>>\mathrm{H}_{2} \mathrm{PO}_{4}{ }^{-}$. Já para o LVdf foi: $\mathrm{NH}_{4}{ }^{+}>\mathrm{NO}_{3}^{-}>\mathrm{K}^{+}>>\mathrm{H}_{2} \mathrm{PO}_{4}{ }^{-}$.

Ressalta-se que os Latossolos apresentam estrutura granular maciça porosa; assim, os resultados obtidos em colunas no laboratório não seriam tão discrepantes do campo. Além disso, trabalhou-se com solo peneirado em peneira de $4 \mathrm{~mm}$ para ficar mais próximo ainda da estrutura de campo, comparando-se com solo peneirado em $2,00 \mathrm{~mm}$.

\section{CONCLUSÕES}

1. A aplicação da dose integral de nutrientes na segunda fração da lâmina de irrigação, ou o fracionamento da dose em duas na segunda e na terceira fração da lâmina de irrigação, é mais indicado na fertirrigação de culturas com sistema radicular de profundidade efetiva maior.

Quadro 5. Contrastes médios comparando a profundidade do maior teor de amônio, nitrato, potássio e fósforo, considerando a fração da lâmina de irrigação (F) em que o nutriente foi aplicado em dose integral (D) ou fracionado em duas $\left(\mathrm{D}_{1 / 2}\right)$ ou em três vezes $\left(\mathrm{D}_{1 / 3}\right)$

\begin{tabular}{|c|c|c|c|c|c|c|c|}
\hline Tratamento & $\mathbf{C}_{1}$ & $\mathrm{C}_{2}$ & $\mathrm{C}_{3}$ & $\mathbf{C}_{4}$ & $\mathbf{C}_{5}$ & $\mathrm{C}_{6}$ & $\mathbf{C}_{7}$ \\
\hline Água & 7 & 0 & 0 & 0 & 0 & 0 & 0 \\
\hline $\mathrm{F}_{2} \mathrm{D}$ & -1 & 4 & 0 & 2 & 0 & 0 & 0 \\
\hline $\mathrm{F}_{3} \mathrm{D}$ & -1 & 4 & 0 & -1 & 1 & 0 & 0 \\
\hline $\mathrm{F}_{4} \mathrm{D}$ & -1 & 4 & 0 & -1 & -1 & 0 & 0 \\
\hline $\mathrm{F}_{2} \mathrm{D}_{1 / 2} \mathrm{~F}_{3} \mathrm{D}_{1 / 2}$ & -1 & -3 & 1 & 0 & 0 & 2 & 0 \\
\hline $\mathrm{F}_{3} \mathrm{D}_{1 / 2} \mathrm{~F}_{4} \mathrm{D}_{1 / 2}$ & -1 & -3 & 1 & 0 & 0 & -1 & 1 \\
\hline $\mathrm{F}_{2} \mathrm{D}_{1 / 2} \mathrm{~F}_{4} \mathrm{D}_{1 / 2}$ & -1 & -3 & 1 & 0 & 0 & -1 & -1 \\
\hline \multirow[t]{2}{*}{$\mathrm{F}_{2} \mathrm{D}_{1 / 3} \mathrm{~F}_{3} \mathrm{D}_{1 / 3} \mathrm{~F}_{4} \mathrm{D}_{1 / 3}$} & -1 & -3 & -3 & 0 & 0 & 0 & 0 \\
\hline & \multicolumn{7}{|c|}{ Amônio (1) (cm) } \\
\hline LVAd1 & $12,0^{* *}$ & $8,8^{* *}$ & $7,0^{* *}$ & $10,5^{\text {*** }}$ & $7,0^{* *}$ & $10,5^{* *}$ & $7,0^{* *}$ \\
\hline LVAd2 & $9,0^{* *}$ & $7,6^{* *}$ & $9,3^{* *}$ & $7,0^{* *}$ & 0,0 & $7,0^{* *}$ & 0,0 \\
\hline LVdf & $12,0^{* *}$ & $12,8^{* *}$ & $-4,7 * *$ & $7,0^{* *}$ & 0,0 & $7,0^{* *}$ & 0,0 \\
\hline \multirow[t]{2}{*}{$\mathrm{LVd}$} & $17,0^{* *}$ & $9,3^{* *}$ & $9,3^{* *}$ & $7,0^{* *}$ & 0,0 & $3,5^{* *}$ & $7,0^{* *}$ \\
\hline & \multicolumn{7}{|c|}{ Nitrato $(\mathrm{cm})$} \\
\hline LVAd1 & $4,3^{* *}$ & $18,5^{* *}$ & $2,3^{*}$ & $8,2^{* *}$ & $7,0^{* *}$ & $7,0^{* *}$ & 0,0 \\
\hline LVAd2 & $6,3^{* *}$ & $7,0^{* *}$ & $9,3^{* *}$ & $10,5^{\text {** }}$ & $7,0^{* *}$ & $-14,0^{* *}$ & $-28,0^{* *}$ \\
\hline LVdf & $15,3^{* *}$ & $9,2^{* *}$ & $2,3^{*}$ & $4,7^{\text {** }}$ & $4,7^{* *}$ & $-3,5^{* *}$ & $-7,0^{* *}$ \\
\hline \multirow[t]{2}{*}{$\mathrm{LVd}$} & $7,3^{* *}$ & $8,8^{* *}$ & $7,0^{* *}$ & $10,5^{* *}$ & $7,0^{* *}$ & $-10,5^{* *}$ & $21,0^{* *}$ \\
\hline & \multicolumn{7}{|c|}{ Potássio (cm) } \\
\hline LVAd1 & $37,3^{* *}$ & 0,0 & 0,0 & 0,0 & 0,0 & 0,0 & 0,0 \\
\hline LVAd2 ${ }^{(2)}$ & $56,0^{\text {** }}$ & 0,0 & 0,0 & 0,0 & 0,0 & 0,0 & 0,0 \\
\hline LVdf & $44,3^{* *}$ & 0,0 & 0,0 & 0,0 & 0,0 & 0,0 & 0,0 \\
\hline \multirow[t]{2}{*}{$\mathrm{LVd}$} & $39,7^{* *}$ & 0,0 & 0,0 & 0,0 & 0,0 & 0,0 & 0,0 \\
\hline & \multicolumn{7}{|c|}{ Fósforo $(\mathrm{cm})$} \\
\hline LVAd1 & $7,0^{*}$ & 0,0 & 0,0 & 0,0 & 0,0 & 0,0 & 0,0 \\
\hline LVAd2 & $42,0^{* *}$ & 0,0 & 0,0 & 0,0 & 0,0 & 0,0 & 0,0 \\
\hline LVdf $2 /$ & $21,0^{* *}$ & 0,0 & 0,0 & 0,0 & 0,0 & 0,0 & 0,0 \\
\hline LVd & $39,7^{* *}$ & 0,0 & 0,0 & 0,0 & 0,0 & 0,0 & 0,0 \\
\hline
\end{tabular}

(1) A análise estatística apresentou variância zero para todos os solos e tratamentos. ${ }^{(2)}$ A análise estatística apresentou variância zero para os tratamentos dentro deste solo. ${ }^{*}, * *$ : Significativos a 5 e $1 \%$, respectivamente, pelo teste F. 
2. A aplicação da dose integral de nutrientes nas últimas frações da lâmina de irrigação (terceira e quarta), ou a diluição da dose em duas na terceira e na quarta fração, é mais indicada para culturas com sistema radicular de profundidade efetiva menor.

3. $\mathrm{O} \mathrm{N}\left(\mathrm{NO}_{3}^{-}\right.$e $\left.\mathrm{NH}_{4}^{+}\right)$e o $\mathrm{K}^{+}$exigem dosagem cuidadosa na solução, para evitar perdas de $\mathrm{N}$ por lixiviação, ou localização superficial do $\mathrm{K}^{+}$, em razão da mobilidade diferencial desses nutrientes, no sentido de prevenir a contaminação de água subterrânea por $\mathrm{NO}_{3}{ }^{-}$e salinização do solo principalmente pelo $\mathrm{K}^{+}$.

4. Os Latossolos estudados apresentam riscos diferentes de contaminação de água subterrânea por $\mathrm{NO}_{3}{ }^{-}$, na seguinte ordem: LVAd1 $>$LVAd2 $>$LVdf $>$ $\mathrm{LVd}$.

5. Recomenda-se a não-aplicação do $\mathrm{H}_{2} \mathrm{PO}_{4}{ }^{-}$via fertirrigação, em razão da sua baixa mobilidade no perfil do solo.

\section{AGRADECIMENTO}

À FAPEMIG, pela concessão da bolsa durante o curso de Doutorado.

\section{LITERATURA CITADA}

ALVAREZ V., V.H. \& ALVAREZ, G.A.M. Comparação de médias ou teste de hipóteses? Contrastes!. Viçosa, MG, Sociedade Brasileira de Ciência do Solo, 2006. (Boletim Informativo)

ALVAREZ V., V.H.; NOVAIS, R.F.; DIAS, L.E. \& OLIVEIRA, J.A. Determinação e uso do fósforo remanescente. B. Inf. SBCS, 25:27-33, 2000.

AFIF, E.; BARRÓN, V. \& TORRENT, J. Organic matter delays but does not prevent phosphate sorption by Cerrado soils from Brazil. Soil Sci., 159:207-211, 1995.

AMARAL, G. Características químicas e físicas de diferentes classes de solos da zona metalúrgica mineira e produtividade de eucalipto. Viçosa, MG, Universidade Federal de Viçosa, 2000. 98p. (Tese de Mestrado)

ANDRADE, F.V.; MENDONÇA, E.S.; ALVAREZ V., V.H. \& NOVAIS, R.F. Adição de ácidos orgânicos e húmicos em Latossolos e adsorção de fosfato. R.Bras. Ci. Solo, 27:10031011, 2003.

ARAÚJO, C.A.S. Movimento de fósforo e de macronutrientes catiônicos em agregados de um Latossolo VermelhoEscuro. Viçosa, MG, Universidade Federal de Viçosa, 1997. 124p. (Tese de Doutorado)

ARAÚJO, A.R.; CARVALHO, J.L.N.; GUILHERME, L.R.G.; CURI, N. \& MARQUES, J.J. Movimentação de nitrato e amônio em colunas de solo. Ci. Agrotec., 28:537-541, 2004.

BRAGA, J.M. \& DEFELIPO, B.V. Determinação epectrofotométrica de fósforo em extratos de solo e material vegetal. $\mathrm{R}$. Ceres, 21:73:85, 1974.
CARRIJO, O.A.; SILVA, W.L.C.; MARQUELLI, W.A. \& SILVA, H.R. Tendências e desafios da fertirrigação no Brasil. In: FOLEGATTI, M.V., coord. Fertirrigação: Citrus, flores, hortaliças. Guaíba, Agropecuária, 1999. p.155-169.

COSTA, S.N.; MARTINEZ, M.A.; MATOS, A.T. \& RAMOS, V.B.N. Mobilidade de nitrato em colunas de solo sob condições de escoamento não permanente. R Bras. Eng. Agríc. Amb., 3:190-194, 1999.

DEFELIPO, B.V. \& RIBEIRO, A.C. Análise química do solo. 2.ed. Viçosa, MG. Universidade Federal de Viçosa, 1997. 26p. (Boletim de Extensão, 29)

DONAGEMMA, G.K. Pré tratamento na análise textural visando a minimização do pseudo-silte em Latossolos de Minas Gerais. Viçosa, MG, Universidade Federal de Viçosa, 2000. 89p. (Tese de Mestrado)

EMPRESA BRASILEIRA DE PESQUISA AGROPECUÁRIA EMBRAPA. Serviço Nacional de Levantamento e Conservação de Solos. Manual de métodos de análise de solo. Rio de Janeiro, 1997. 212p.

ESPINOZA, W. \& REIS, A.E.G. Lixiviação em Latossolo Vermelho Escuro do Cerrado II. Magnitude e variabilidade do fenômeno sob irrigação. Pesq. Agropec. Bras., 19:8594, 1984.

FESCH, C.; LEHMAN, P.; HADERLEIN, S.B.; HINZ, C.; SCHARZENBACH, R.P. \& FLUHLER, H. Effect of water content on solute transport in a porous medium containing reactive micro-agreggates. J. Contam. Hydrol., 33:211230,1998

FRIZZONE， J.A.; ZANINI， J.R.; PAES， L.A.D. \& NASCIMENTO, V.M. Fertirrigação mineral. Ilha Solteira, Universidade Estadual de São Paulo, 1985. 31p.

GONÇALVES, J.L.M.; FIRME, D.J.; NOVAIS, R.F. \& RIBEIRO, A.C. Cinética de adsorção de fósforo em solos de Cerrado. R. Bras. Ci. Solo, 9:107-111, 1985.

GRANT, R.F. \& HEANEY, D.J. Inorganic transformation and transport in soils: Mathematical modeling in ecosystem. Soil Sci. Soc. Am. J., 61:752-764, 1997.

GRIFFIOEN, J. Potassium adsorption ratios as an indicator for the fate of agricultural potassium in ground water. J. Hidrol., 254:244-254, 2001.

HERNANDEZ, F.B.T. Potencialidades da fertirrigação. In: VITTI, G.C. \& BOARRETO, A.E., eds. Fertilizantes fluidos. Piracicaba, 1993. Anais. Piracicaba, Escola Superior de Agricultura Luiz de Queiroz, 1993. p.199210.

JACOBSEN, O.H.; MOLDRUP, P.; LARSEN, C.; KONNERUP, L. \& PETERSEN, L.W. Particle transport in macroporous of undisturbed soil columns. J. Hidrol., 196:185-203, 1997.

JENSEN, M.B.; JORGESEN, P.R.; HANSEN, H.C.B. \& NIELSEN, N.E. Biopore mediated subsurface transport of dissolved orthophosphate. J. Environ. Qual., 27:11301137, 1998.

KEMPERS, A.J. \& ZEWERS, W.L. Ammonium determination in soil extracts by salicylate method. Comm. Soil Sci. Plant. Anal., 17:715-723, 1986 
KIRKBY, C.A.; SMYTH, L.J.; COX, J.W. \& CHITTLEBOROUGH, D.J. Phosphorus movement down topsequence from a landscape with texture contrast soils. Aust. J. Soil Res., 35:399-417, 1997.

NOVAIS, R.F. \& SMYTH, T.J. Fósforo em solo e planta em condições tropicais. Viçosa, MG, Universidade Federal de Viçosa, 1999. 399p.

OLIVEIRA, L.R.A.; VILELA, L.E. \& ANGELAYARZA, M. Adsorção de nitrato em solos de Cerrado do Distrito Federal. Pesq. Agropec. Bras., 35:1199-1205, 2000.

OLIVEIRA, E.M.M.; RUIZ, H.A.; FERREIRA, P.A.; ALVAREZ V., V.H. \& BORGES JÚNIOR, J.C.F. Fatores de retardamento e coeficientes de dispersão-difusão de fosfato, potássio e amônio em solos de Minas Gerais. R. Eng. Agric. Amb., 8:196-203, 2004.

PADILLA, I.Y.; JIM YEH, T.C. \& CONKLIN, M.H. The effect of water content on solute transport in unsatured porous media. Water Res. Res., 35:3303-3313, 1999.

PINHEIRO, R.B. Mobilidade de nitrato em resposta a propriedades eletroquímicas de solos com carga variável. Viçosa, MG, Universidade Federal de Viçosa, 2002. 76p. (Tese de Mestrado)

PINTO, J.M. Fertirrigação em fruticultura irrigada. Item, 49:14-23, 2001

QAFOKU, N.P.; SUMNER, M.E. \& RADCLIFFE, D.E. Anion transport in columns of variable charge subsoils: Nitrate and cloride. J. Envirom. Qual., 29:484-493, 2000.

QAFOKU, N.P. \& SUMNER, M.E. Retention and transport of calcium nitrate in variable charge subsoils. Soil Sci., 166:299-307, 2001.

RAIJ, B.van. Avaliação da fertilidade do solo. Piracicaba, Instituto Internacional da Potassa, 1981. 343p.

RUIZ, H.A. Métodos de análises físicas do solo. Viçosa, MG, Universidade Federal de Viçosa, 2004. 22p. (Notas de aula)

RUIZ, H.A. Incremento da exatidão da análise granulométrica do solo por meio da coleta da suspensão (silte + argila). $R$. Bras. Ci. Solo, 29:297-300, 2005.
SANTOS NETO, J.A. Taxas de recuperação de zinco, cobre e boro por diferentes extratores em solos da Bahia e de Minas Gerais. Viçosa, MG, Universidade Federal de Viçosa, 2003. 50p. (Tese de Mestrado)

SCHUMMAN, L.M. Phosphate and nitrate moviment trough simulated golf greens. Water Air Soil Pollut., 129:305318, 2001.

SHIPTALO, M.J.; DICK, W.A. \& EDWARDS, W.M. Conservation tillage and macropore factors that affect water movement and the fate of chemicals. Soil Till. Res., $53: 167-183,2000$

SILVA, A.S. Movimentação de amônio, nitrato, potássio e fósforo aplicados por fertirrigação em Latossolos. Viçosa, MG, Universidade Federal de Viçosa, 2004. 58p. (Tese de Mestrado)

VILLAS BOAS, R.L.; BOARETTO, A.E. \& VITTI, G.C. SIMPÓSIO BRASILEIRO SOBRE FERTILIZANTES FLUIDOS, 1., Piracicaba, 1994. Anais. Piracicaba, POTAFOS, 1994. p.284-308.

WADT, P.G.S. \& WADT, L.H.O. Movimentação de cátions em Latossolo Vermelho-Amarelo incubado com duas fontes de cálcio. R. Sci Agric., 56:1157-1164, 1999.

WANG, F.L. \& ALVA, A.K. Ammonium adsorption and desorption in sandy soils. Soil Sci. Soc. Am. J., 64:16691674, 2000.

YANG, J.E.; SKOGLEY. E.O.; SCHAFF, B.E. \& KIM, J.J. A simple spectrophotometric determination of nitrate in water, resin and soil extracts. Soil Sci. Soc. Am. J., 62:1108$1115,1998$.

YEOMANS, J.C. \& BREMNER, J.M. A rapid and precise method for routine determination of carbon in soil. Comm. Soil Sci. Plant Anal., 19:1467-1476, 1988.

ZONTA, E.; BRASIL, F.C.; GOI, S.R. \& ROSA, M.M.T. O sistema radicular e suas interações com o ambiente edáfico. In: FERNANDES, M.S., ed. Nutrição mineral de plantas. Viçosa, MG, Sociedade Brasileira de Ciência do Solo, 2006. p.8-28. 